\title{
Pengujian Analisis Tegangan Tembus Minyak Transformator 60 MVA Di Gis Kebun Jeruk
}

\author{
Sofitri Rahayu'; Rudina Aita Diantari²; Retno Aita Diantari ${ }^{3}$ \\ 1, 2, 3 Program Studi Teknik Elektro, Sekolah Tinggi Teknik PLN \\ 1'sofitri@sttpln.ac.id \\ 2 retno.aita@sttpln.ac.id \\ ${ }^{3}$ rudina.okvasari@sttpln.ac.id
}

\begin{abstract}
Transformer oil functions as insulation and cooling, it also has the property of dissolving gases arising from system damage. The use of transformers everywhere is the same, specifically for power transformers, namely as an increase or decrease voltage adjust the voltage of the machine itself. By carrying out periodic maintenance and controlling the transformer during operation, more benefits will be obtained, including: increasing obtained from the transformer, extending the service life, if the service life is longer, it will automatically help buy unit transformers. While the transformer maintenance steps are one of them is periodic inspection of the quality of insulating oil. The purpose of this study was to analyze the characteristics of oil transformers carried out in substations with a standard value of breakdown voltage based on SPLN'50-1982 and IEC No. 56 of 1991 is $\geq 30 \mathrm{kV}$ / $2.5 \mathrm{~mm}$. From the test results, it can be seen that the average value of transformer 2 oil voltage is $23.7 \mathrm{KV} / 2.5 \mathrm{~mm}$ and the average values of transformer 3 oil voltage are 32.7 $\mathrm{KV} / 2.5 \mathrm{~mm}$. Transformer 2 oil is below $30 \mathrm{kV} / 2.5 \mathrm{~mm}$ which means that the transformer oil must be repaired further. While for transformer 3 oil, the value is below the standard 30 $\mathrm{kV} / 2.5 \mathrm{~mm}$ which means that the oil is still good to use.
\end{abstract}

Keywords: oil transformer, breakdown voltage, substation

\begin{abstract}
ABSTRAK
Minyak transformator berfungsi sebagai isolasi dan pendingin, juga mempunyai sifat dapat melarutkan gas-gas yang timbul akibat kerusakan sistem. Penggunaan transformator dimanapun adalah sama, khususnya untuk tranformator daya, yaitu sebagai penaik atau penurun tegangan menyesuaikan tegangan dari mesin itu sendiri. Dengan melakukan perawatan secara berkala dan pemantauan kondisi transformator pada saat beroperasi akan banyak keuntungan yang didapat, antara lain: meningkatkan keandalan dari transformator tersebut, memperpanjang masa pakai, jika masa pakai lebih panjang, maka secara otomatis akan dapat menghemat biaya penggantian unit transformator. Adapun langkah-langkah perawatan transformator salah satun ya adalah pemeriksaan berkala kualitas minyak isolasi. Tujuan dari penelitian ini adalah untuk menganalisis karakteristik dari minyak transformator yang dilakukan pemeriksaan secara berkala di Gardu Induk dengan nilai standar nilai tegangan tembus menurut SPLN'50-1982 dan IEC No. 56 tahun 1991 adalah sebesar $\geq 30 \mathrm{kV} / 2,5 \mathrm{~mm}$. Dari hasil pengujian dapat diketahui bahwa nilai ratarata tegangan tembus minyak trafo 2 sebesar 23,7 KV/2,5 $\mathrm{mm}$ dan nilai-nilai rata-rata tegangan tembus minyak trafo 3 sebesar 32,7 KV/2,5 mm. Sehingga dapat dilakukan analisa bahwa untuk tegangan tembus minyak trafo 2 di bawah $30 \mathrm{kV} / 2,5 \mathrm{~mm}$ yang artinya minyak trafo sudah harus dilakukan penanganan lebih lanjut. Sedangkan untuk minyak trafo 3, nilainya diatas di bawah standar $30 \mathrm{kV} / 2,5 \mathrm{~mm}$ yang artinya minyak tersebut masih baik untuk digunakan.
\end{abstract}

Kata kunci: minyak transformator, tegangan tembus, gardu induk 


\section{PENDAHULUAN}

Bagian Pendahuluan membahas latar belakang masalah, tinjauan pustaka secara ringkas, maksud dan tujuan riset dilakukan. Pendahuluan sebaiknya berisi perkembangan penelitian terdahulu (state of the art) untuk membandingkan dengan penelitian yang dilakukan saat ini sehingga tampil kesenjangan antara teori atau hasil penelitian terdahulu dengan keadaan saat ini atau yang diharapkan Transformator adalah salah satu alat penunjang ketersedian pasokan listrik dari PLN ke konsumen. Tugas transformator dengan cara merubah tegangan dari tegangan menengah menjadi tegangan yang lebih rendah atau sebaliknya. Transformator memiliki peranan yang sangat penting dalam pendistribusian listrik seperti yang dilakukan oleh PLN, transformator juga memiliki peranan penting dalam pendistribusian listrik dari PLN ke gedung - gedung pengguna daya listrik dari PLN. Sarana dan atau prasarana akan mengalami penurunan unjuk kerja sesuai dengan perjalanan waktu (umur) serta upaya pemeliharaaan yang dilakukan. Dengan realitas tersebut pemeliharaan dan/ atau perawatan sarana dan prasarana mempunyai peran yang sangat penting guna menjaga kehandalannya. Kelangsungan operasi dari transformator sangat bergantung pada umur dan kualitas sistem isolasinya, terutama adalah kualitas isolasi minyak transformator.

Minyak transformator berfungsi sebagai isolasi dan pendingin, juga mempunyai sifat dapat melarutkan gas-gas yang timbul akibat kerusakan sistem. Penggunaan transformator dimanapun adalah sama, khususnya untuk tranformator daya, yaitu sebagai penaik atau penurun tegangan menyesuaikan tegangan dari mesin itu sendiri. Pemeliharaan tidak saja merupakan pekerjaan fisik yang langsung terhadap peralatan yang bersangkutan, melainkan diperlukan suatu perencanaan yang baik dan pengawasan terhadap pelaksanaanya. Sehingga dengan demikian pemeliharaan dapat dilakukan dengan teratur dan sesuai dengan ketentuan-ketentuan dan petunjuk yang berlaku terhadap peralatan yang bersangkutan. Dengan melakukan perawatan secara berkala dan pemantauan kondisi transformator pada saat beroperasi akan banyak keuntungan yang didapat, antara lain: meningkatkan keandalan dari transformator tersebut, memperpanjang masa pakai, jika masa pakai lebih panjang, maka secara otomatis akan dapat menghemat biaya penggantian unit transformator. Adapun langkah-langkah perawatan transformator salah satuya adalah pemeriksaan berkala kualitas minyak isolasi.

Tujuan dari penelitian ini adalah untuk menganalisis karakteristik dari minyak transformator yang dilakukan pemeriksaan secara berkala di Gardu Induk.

\section{METODE/PERANCANGAN PENELITIAN}

Metode yang digunakan pada penelitian ini yaitu observasi. Dimana peneliti melakukan pengamatan langsung terhadap objek yang diteliti untuk mengamati keadaan yang sebenarnya di lapangan. Dalam hal ini, pengamatan dilakukan di PT. PLN (PERERO) GIS Kebun Jeruk. Untuk membantu dalam penyusunan penelitian ini, maka perlu adanya susunan kerangka kerja (frame work) yang jelas tahapan-tahapannya seperti terlihat pada gambar 2.1 di bawah ini. 


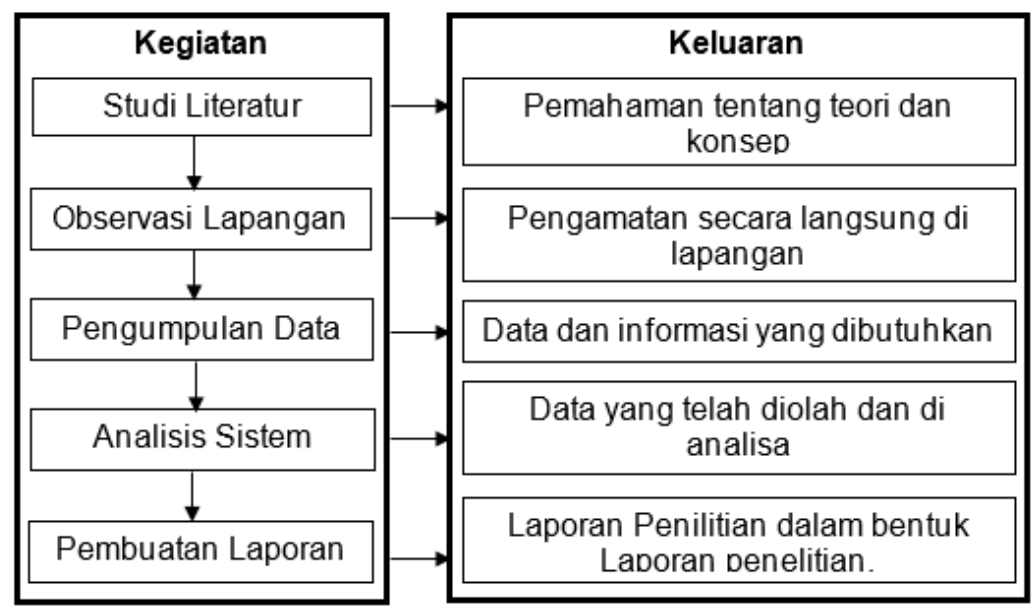

Gambar 1. Kerangka Kerja Penelitian

Berdasarkan kerangka kerja penelitian yang telah digambarkan di atas, maka dapat diuraikan pembahasan masing-masing tahap dalam penelitian adalah sebagai berikut :

\section{a. Studi Literatur}

Pada tahap ini dilakukan pencarian landasan-landasan teori yang diperoleh dari berbagai buku, jurnal dan lain-lain untuk melengkapi perbendaharaan konsep dan teori, sehingga memiliki landasan dan keilmuan yang baik dan sesuai.

b. Observasi Lapangan

Pada tahap ini dilakukan pengamatan secara langsung di lapangan tempat peneliti melakukan penelitian.

\section{c. Pengumpulan Data}

Pada tahap ini dilakukan proses pengumpulan data dengan metode wawancara dan observasi untuk melakukan pengamatan dan analisa terhadap objek penelitian sehinggan mendapatkan data dan informasi yang dibutuhkan peneliti.

d. Analisis Sistem

Pada tahap ini peneliti telah memperoleh data-data yang dibutuhkan dalam penelitian yang mana kemudian data-data ini akan diolah, dianalisa dan dievaluasi untuk mendapatkan hasil penelitian yang sesuai kebutuhan.

e. Pembuatan Laporan

Pada tahapan ini dilakukan pembuatan laporan yang disusun berdasarkan hasil penelitian dengan menggunakan teknik pengumpulan data primer dan sekunder sehingga menjadi laporan penelitian yang dapat memberikan gambaran penelitian secara utuh.

Langkah-langkah yang dilakukan dalam melakukan pengujian tegangan tembus dapat dilihat seperti pada gambar diagram alir berikut ini: 


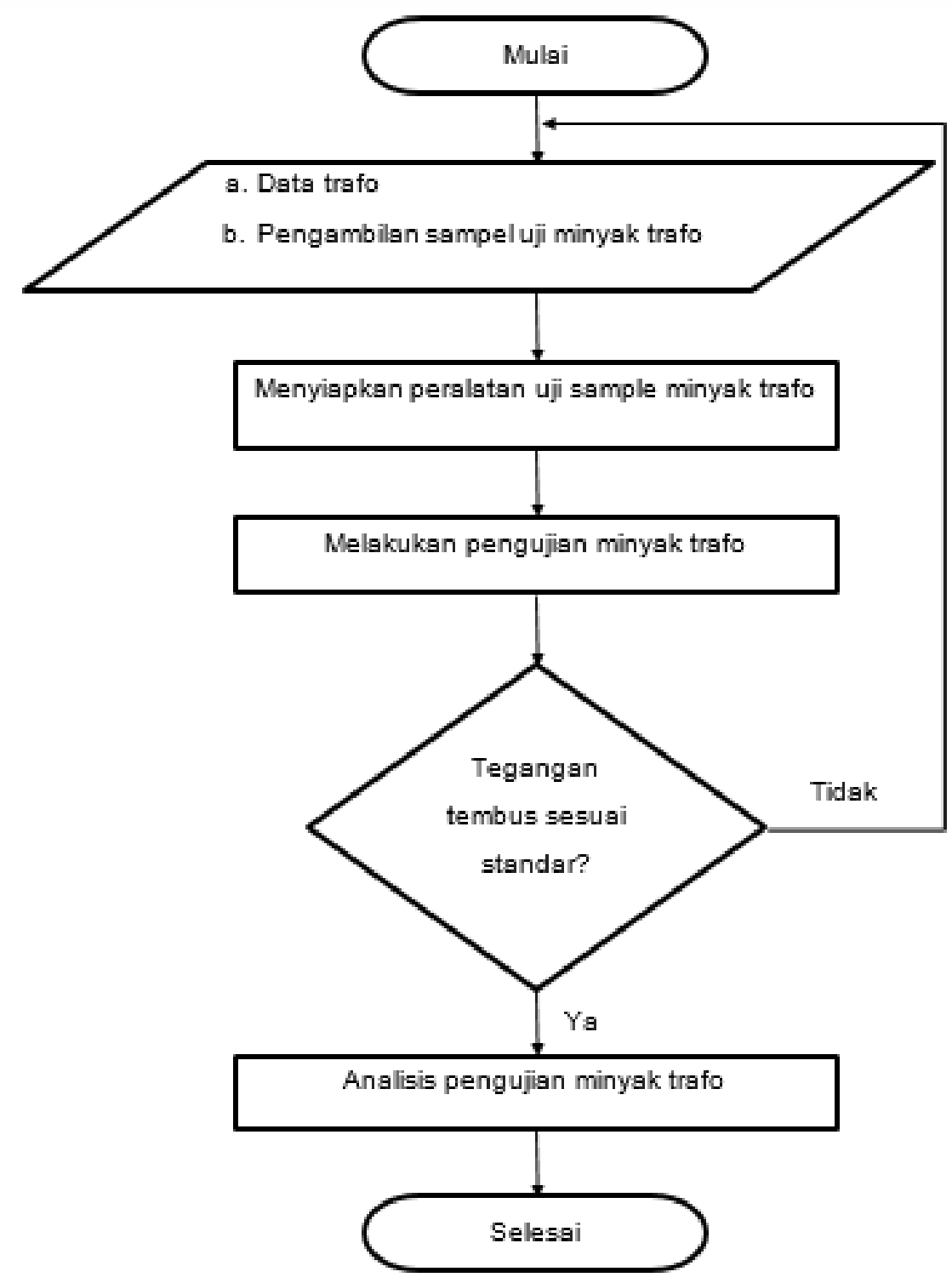

Gambar 2. Diagram Alir Proses Pengujian Tegangan Tembus Minyak Trafo

\subsection{Elektroda Uji}

Elektroda uji terbuat dari bahan alumunium yang terdiri dari beberapa macam, yaitu elektroda setengah bola, bola dan bidang.

\subsubsection{Elektroda setengah bola}

Elektroda ini mempunyai diameter 40,50, dan $60 \mathrm{~mm}$ dengan elektroda setengah bola diameter $50 \mathrm{~mm}$ disesuaikan standarisasi IEC 156 dan diameter lainnya sebagai pembanding. 

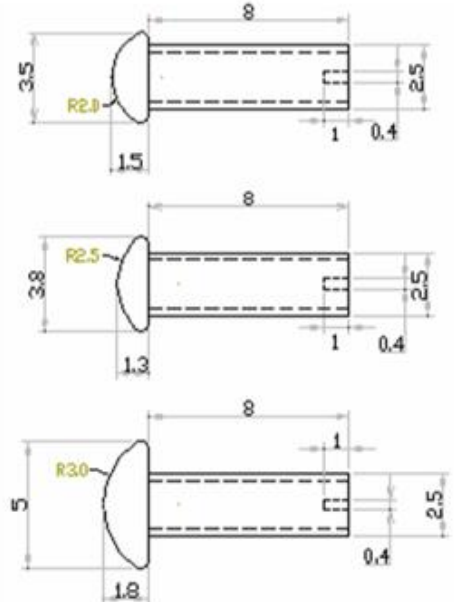

(a)
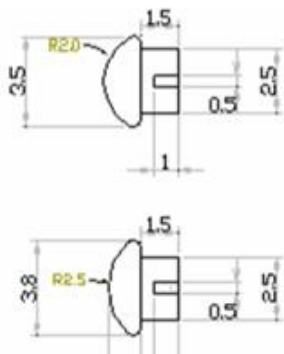

13. 1 .

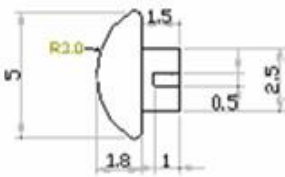

(b)

Gambar 3. Elektroda setengah bola

(a) elektroda setengah bola posisi vertical; (b) elektroda setengah bola posisi horizontal

\subsubsection{Elektroda Bola}

Elektroda bola mempunyai diameter 20, 25, dan $30 \mathrm{~mm}$.
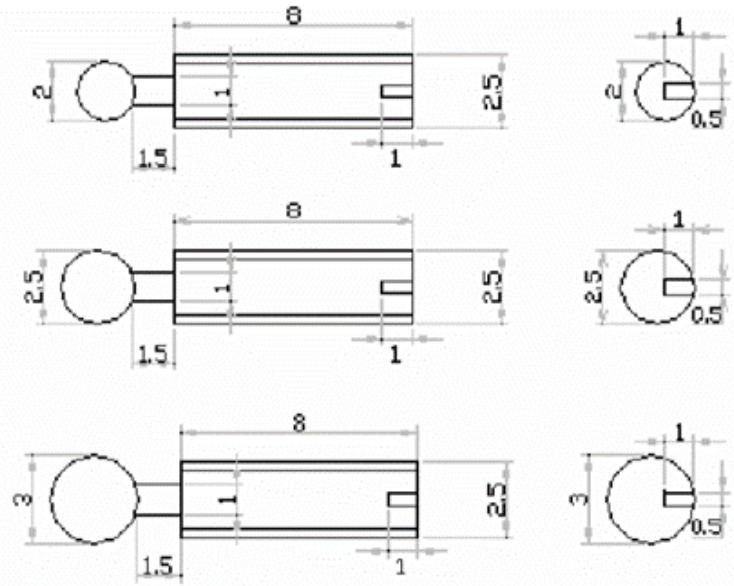

(a)

(b)

Gambar 4. Elektroda bola

(a) elektroda bola posisi vertikal (b) elektroda bola posisi horizontal

\subsubsection{Elektroda Bidang}

Dipakai elektroda bidang diameter $45 \mathrm{~mm}$ dan secara khusus dipasangkan dengan elektroda bola diameter $20 \mathrm{~mm}$ untuk melakukan pengujian pengaruh medan tak seragam.

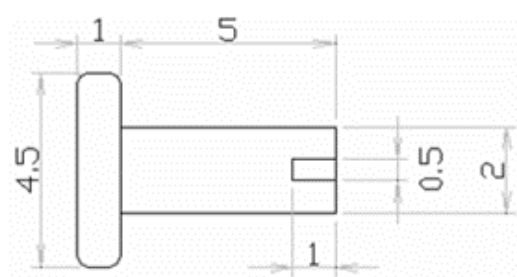

Gambar 5. Elektroda bidang 


\subsection{Kotak Uji}

Kotak uji adalah sebagai sebuah sistem yang berkaitan dengan kerja tertentu dalam ruang dan keseluruhan ruang yang ditutupi oleh lapisan permukaan sebagai pembatas sistem. Kotak uji terbuat dari bahan plastik acrylic. Kotak uji mempunyai dimensi luar yaitu untuk posisi horisontal dengan panjang $100 \mathrm{~mm}$, lebar $150 \mathrm{~mm}$ dan tinggi $150 \mathrm{~mm}$. Sedangkan untuk posisi vertikal dengan panjang $100 \mathrm{~mm}$, lebar $150 \mathrm{~mm}$ dan tinggi 150 $\mathrm{mm}$. Khusus pengujian medan tak seragam menggunkan kotak uji horizontal ukuran panjang $180 \mathrm{~mm}$, lebar $150 \mathrm{~mm}$ dan tinggi $150 \mathrm{~mm}$. Kotak uji digunakan untuk meletakkan elektroda uji dan sebagai wadah isolasi cair yang dimasukkan dalam sistem untuk pengujian tegangan tembus.
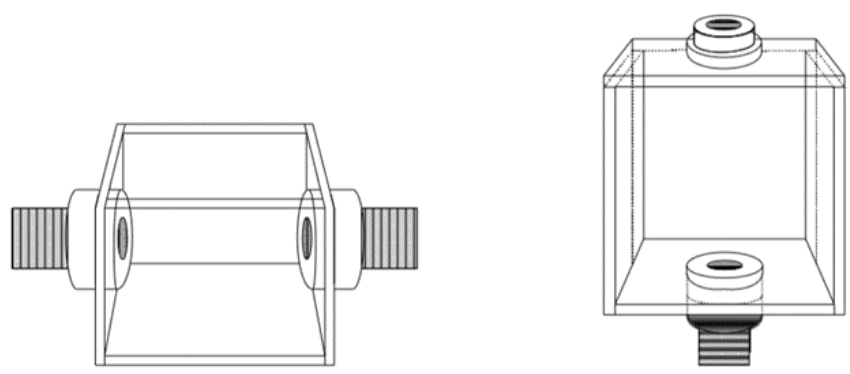

Gambar 6. Kotak uji horisontal dan vertical

\subsection{Rangkaian Pengujian}

Gambar berikut adalah rangkaian yang digunakan untuk melakukan pengujian tegangan tembus minyak transformator.

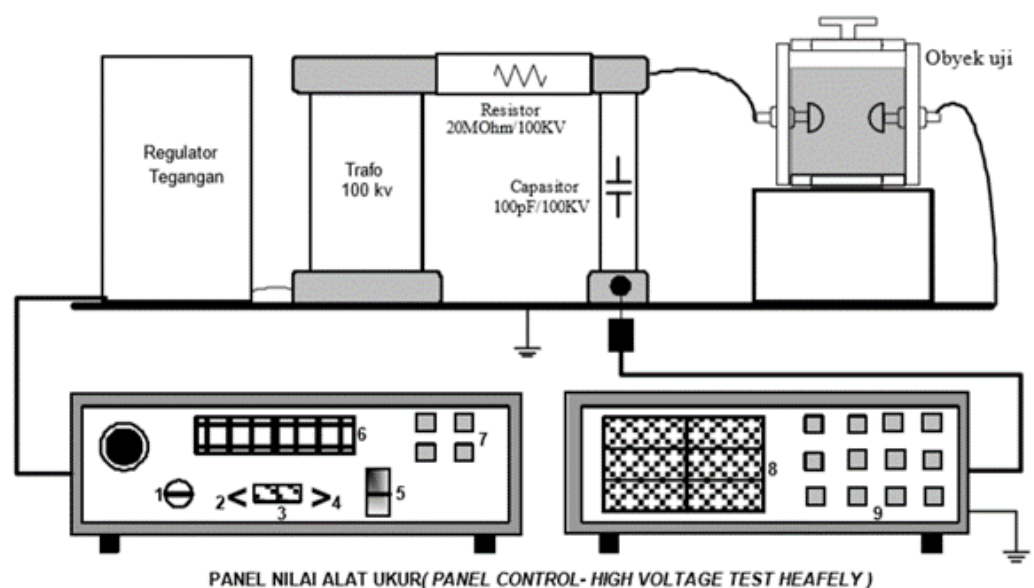

(a)

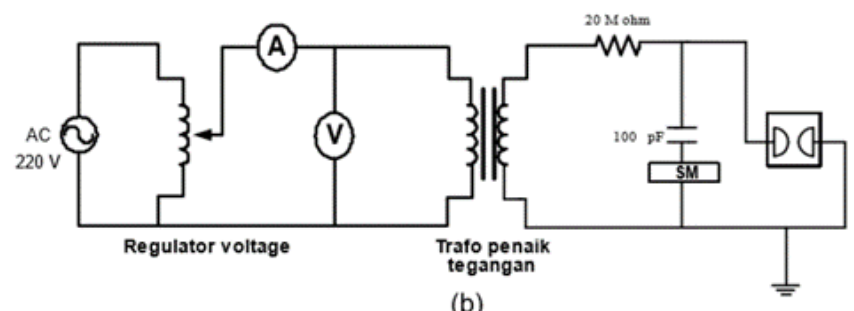

(b)

Gambar 7. Rangkaian Pengujian

(a) Bagan peralatan uji (b) Rangkaian pengujian 


\section{HASIL DAN PEMBAHASAN}

\subsection{Pengujian Tegangan Tembus Minyak Trafo GIS Kebun Jeruk}

Pengujian minyak transformator dalam penelitian ini menggunakan sampel minyak yang diambil dari Trafo 2 dan Trafo 3 GIS Kebun Jeruk yang dilakukan pada hari Selasa tanggal 18 Juni 2019.

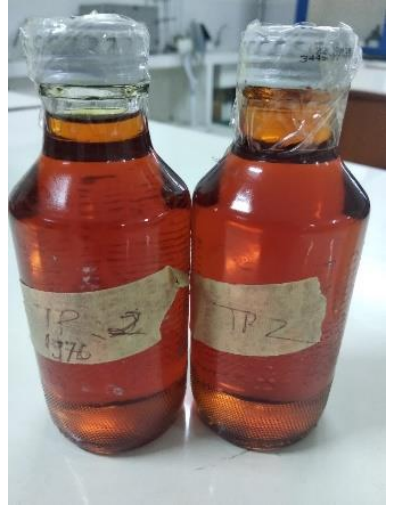

(a)

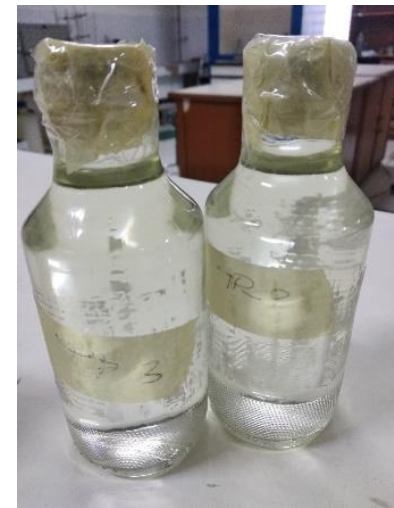

(b)

Gambar 8. Sampel Minyak GIS Kebun Jeruk (a )Trafo 2 (b) Trafo 3

Dari sampel minyak yang telah diambil, kemudian dilakukan pengujian tegangan tembus yang dilakukan di Laboratorium Kimia STT-PLN.
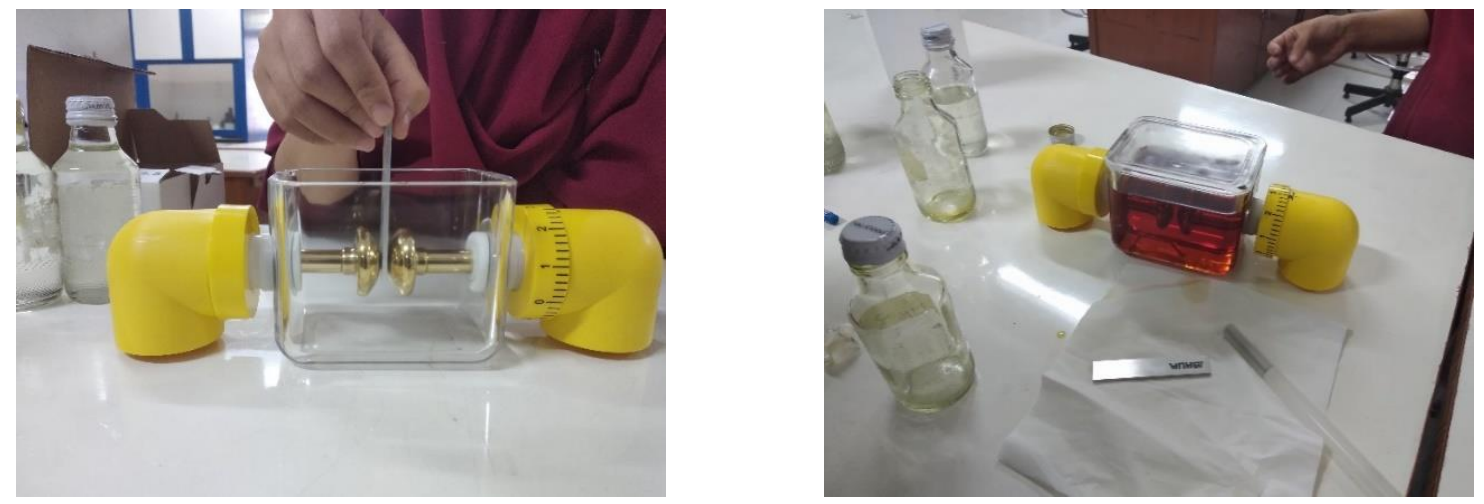

Gambar 9. Proses Pengujian Tegangan Tembus Minyak Trafo

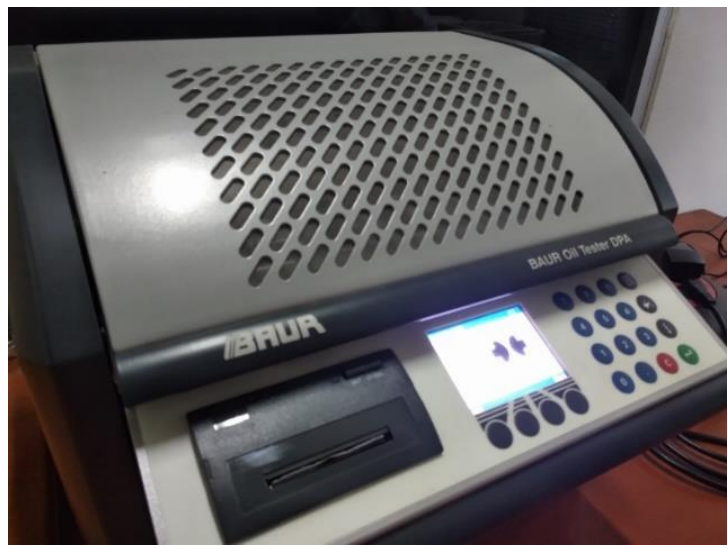

Gambar 10. Alat BDV Test 
Hasil Pengujian Tegangan Tembus Minyak Trafo 2 GIS Kebun Jeruk dapat dilihat pada tabel dibawah ini :

Tabel 1. Hasil Pengujian Tegangan Tembus Minyak Trafo 2 GIS Kebun Jeruk

\begin{tabular}{|c|c|c|}
\hline NO & PENGUKURAN KE- & TEGANGAN TEMBUS (KV) \\
\hline 1 & $\mathrm{I}$ & 16,9 \\
\hline 2 & $\mathrm{II}$ & 17,7 \\
\hline 3 & $\mathrm{III}$ & 28,0 \\
\hline 4 & $\mathrm{IV}$ & 22,6 \\
\hline 5 & $\mathrm{~V}$ & 29,7 \\
\hline 6 & $\mathrm{VI}$ & 27,0 \\
\hline \multicolumn{2}{|c|}{ TEGANGAN RATA-RATA } & 23,7 \\
\hline
\end{tabular}

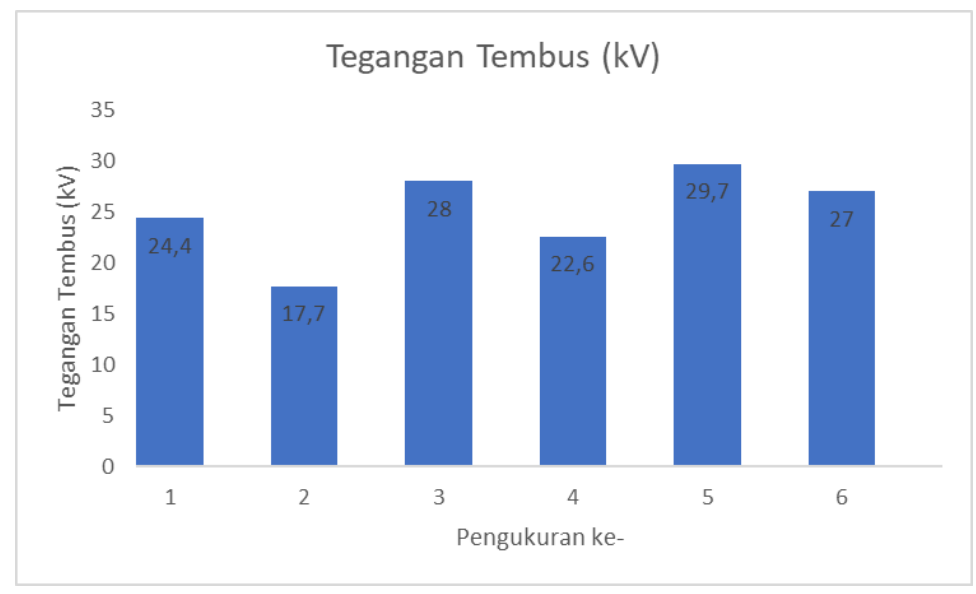

Gambar 11. Grafik Hasil Pengujian Tegangan Tembus Minyak Trafo 2 GIS Kebun Jeruk

Sedangkan hasil Pengujian Tegangan Tembus Minyak Trafo 3 GIS Kebun Jerik dapat dilihat pada tabel dibawah ini :

Tabel 2. Hasil Pengujian Tegangan Tembus Minyak Trafo 3 GIS Kebun Jeruk

\begin{tabular}{|c|c|c|}
\hline No & PENGUKURAN KE- & TEGANGAN TEMBUS (KV) \\
\hline 1 & $\mathrm{I}$ & 24,4 \\
\hline 2 & $\mathrm{II}$ & 32,8 \\
\hline 3 & $\mathrm{II}$ & 35,5 \\
\hline 4 & $\mathrm{IV}$ & 31,9 \\
\hline 5 & $\mathrm{~V}$ & 33,9 \\
\hline 6 & $\mathrm{VI}$ & 37,8 \\
\hline \multicolumn{2}{|c|}{ TEGANGAN RATA-RATA } & 32,7 \\
\hline
\end{tabular}




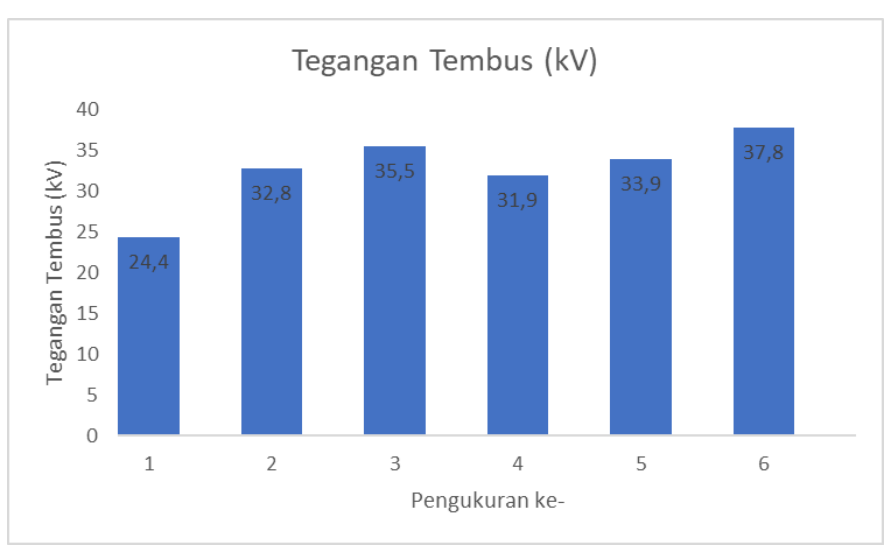

Gambar 12. Grafik Hasil Pengujian Tegangan Tembus Minyak Trafo 3 GIS Kebun Jeruk

\subsection{Analisis Hasil Pengujian Tegangan Tembus Minyak Trafo GIS Kebun Jeruk}

Dari hasil pengujian tersebut dapat diketahui bahwa nilai rata-rata tegangan tembus minyak trafo 2 sebesar $23,7 \mathrm{KV} / 2,5 \mathrm{~mm}$ dan nilai rata-rata tegangan tembus minyak trafo 3 sebesar 32,7 KV/2,5 mm. Standar nilai tegangan tembus menurut SPLN'50-1982 dan IEC No. 56 tahun 1991 adalah sebesar $\geq 30 \mathrm{kV} / 2,5 \mathrm{~mm}$. Sehingga dapat dilakukan analisa bahwa untuk tegangan tembus minyak trafo 2 di bawah $30 \mathrm{kV} / 2,5 \mathrm{~mm}$ yang artinya minyak trafo sudah harus dilakukan penanganan lebih lanjut. Sedangkan untuk minyak trafo 3 , nilainya diatas di bawah standar $30 \mathrm{kV} / 2,5 \mathrm{~mm}$ yang artinya minyak tersebut masih baik untuk digunakan

Adanya perubahan tegangan tembus minyak trafo disebabkan karena adanya partikel uap air dalam minyak yang dipengaruhi oleh perubahan pembebanan pada trafo maupun perubahan temperatur dari udara luar. Ketika temperatur minyak tinggi, minyak akan memuai dan mendesak udara di atas permukaan minyak keluar dari dalam tangki. Sebaliknya, ketika temperatur minyak turun, minyak menyusut sehingga udara luar akan masuk ke dalam tangki. Kedua proses di atas disebut pernapasan trafo. Permukaan minyak trafo akan selalu bersinggungan dengan udara luar sehingga uap air dalam udara masuk ke minyak trafo dan menurunkan nilai tegangan tembus minyak trafo.

\section{KESIMPULAN DAN SARAN}

Dari penelitian yang telah dilakukan, maka dapat disimpulkan bahwa minyak trafo 2 GIS Kebun Jeruk dalam kondisi tidak baik dan perlu dilakukan penanganan lebih lanjut dilihat dari hasil pengujian tegangan tembus sebesar $23,7 \mathrm{KV} / 2,5 \mathrm{~mm}(<30 \mathrm{kV} / 2,5 \mathrm{~mm})$. Sedangkan minyak trafo 3 GIS Kebun jeruk masih baik atau masih layak digunakan karena dari hasil pengujian didapatkan nilai tegangan tembusnya sebesar $32,7 \mathrm{KV} / 2,5 \mathrm{~mm}$.

\section{UCAPAN TERIMAKASIH}

Penulis mengucapkan terima kasih kepada Ketua STT-PLN, kepala LPPM dan kepada Kepala Departemen Elektro yang telah memberi dukungan yang membantu pelaksanaan penelitian dan atau penulisan artikel ini. 


\section{DAFTAR PUSTAKA}

[1] Herviany, S., Yuningtyastuti, \& Syakur, A. ( September 2015). Analisis Perbandingan Karakteristik Dielektrik pada Minyak Bekas Transformator $20 \mathrm{kV}$ Sebelum dan Setelah Purifikasi dengan Adsorben. Transient, Vol. 4, No. 3, 734-744.

[2] Kadir, A. (1989). Transformator Edisi Revisi. Jakarta: PT Elex Media Komputindo.

[3] Nugraha, Ferry. (2007). Pengujian Karakteristik Minyak Isolasi. Jakarta : Litbang Ketanaglistrikan

[4] Reclamation, Bureau. (April 2005).Transformers: Basics, Maintenance, and Diagnostics.Colorado:Hydroelectric Research and Technical Services Group 